Revue

Revue de l'histoire des religions

de Ihistoire

des religions

$1 \mid 2008$

Varia

\title{
Laurence Lux-Sterritt,Redefining Female Religious Life: French Ursulines and English Ladies in seventeenth-century Catholicism
}

Sophie Houdard

\section{OpenEdition}

Journals

Édition électronique

URL : http://journals.openedition.org/rhr/5793

DOI : 10.4000/rhr.5793

ISSN : 2105-2573

Éditeur

Armand Colin

Édition imprimée

Date de publication : 1 mars 2008

Pagination : 140-145

ISBN : 978-2200-92443-0

ISSN : 0035-1423

Référence électronique

Sophie Houdard, « Laurence Lux-Sterritt,Redefining Female Religious Life: French Ursulines and

English Ladies in seventeenth-century Catholicism », Revue de I'histoire des religions [En ligne], 1 | 2008,

mis en ligne le 12 janvier 2010, consulté le 22 septembre 2020. URL : http://journals.openedition.org/ rhr/5793 ; DOI : https://doi.org/10.4000/rhr.5793

Ce document a été généré automatiquement le 22 septembre 2020.

Tous droits réservés 


\title{
Laurence Lux-Sterritt,Redefining Female Religious Life: French Ursulines and English Ladies in seventeenth-century Catholicism
}

\author{
Sophie Houdard
}

\section{RÉFÉRENCE}

Laurence Lux-Sterritt,Redefining Female Religious Life: French Ursulines and English Ladies in seventeenth-century Catholicism, Aldershot, Ashgate Publishing Limited, 2005, 236 p., 24 cm (« Catholic Christendom, 1300-1700»), £50.

1 L'ouvrage de L. Lux-Sterritt se situe au cœur du renouvellement des études d'histoire religieuse entrepris depuis quelques années pour évaluer la place du genre dans l'entreprise de la Contre-Réforme catholique. Une large bibliographie européenne (où manquent cependant étrangement les travaux de B. Diefendorf) confirme la place de cette étude dans les nouvelles perspectives offertes par les sciences sociales et les cultural studies.

2 Partant de l'évidence que les femmes ont été des contributrices importantes à l'activisme catholique au début de l'époque moderne, l'auteure se donne comme but de sortir de la dichotomie stérile dans laquelle s'enferme l'historiographie prise entre l'idée qu'existe une spiritualité « essentiellement " féminine et sans histoire ou celle d'une institution fatalement répressive face à l'émergence d'un rôle offert aux femmes (p. 2). Pour sortir de l'impasse, L. Lux-Sterritt choisit d'examiner deux cas à partir desquels elle propose une étude détaillée des modalités d'agency féminine dans la religion, soit des usages et des pratiques religieux et institutionnels inventés par des femmes. 
3 Comme on le sait, les ordres masculins, rénovés ou créés au moment de la ContreRéforme, choisissent de pénétrer par capillarité les univers sociaux, en adoptant une vie séculière. Les ordres nouveaux, comme les Jésuites, s'adressent aux individus dans le monde, selon les principes d'une dévotion qu'on appelle justement "civile » et que deux évêques, François de Sales et Jean-Pierre Camus, s'emploient à définir. Des femmes, désireuses de participer à ce mouvement de reconquête, exigent à leur tour une sorte de "parité » qui leur laisserait la possibilité d'agir dans le monde, sous la forme de la "vie mixte mêlée de la contemplation et de l'action » (p. 38). Les premières Ursulines françaises et les Dames Anglaises de Mary Ward en Angleterre, étudiées par L. Lux-Sterritt, se lancent donc dans des missions intérieures, spirituelles et morales, dont la clé de voûte est l'éducation des filles, qu'elles veulent gagner en leur offrant un enseignement non cloîtré.

4 Les premières Ursulines françaises choisissent donc de se regrouper sous la forme de communautés laïques. Ces congrégées s'installent ainsi, dans les premières décennies du XVII ${ }^{\mathrm{e}}$ siècle, dans une zone de droit équivoque : aucun « état ", au sens juridique, ne les désigne, puisqu'elles entendent renoncer à l'identification civile fixée par le droit (veuve, femme mariée, fille célibataire ou libre), tout en refusant de s'inscrire, par les vœux et le cloître, dans une identité ecclésiastique. Ces «limbes » juridiques (p. 4), au départ créateurs et libérateurs, finissent par faire obstacle à leur installation, suscitant de nombreux scandales et réactions inquiètes devant cette nouveauté qu'aucun droit n'encadre et que de rares institutions (monarchique, ecclésiastique ou municipale) sont prêtes à soutenir. Comme le montrent les exemples cités par L. Lux-Sterrit, des «batailles publiques » entourent l'installation de ces femmes qui, à Toulouse, Brive-laGaillarde, Agen rencontrent une hostilité presque générale devant leurs modes de vie " vagabonds ", qui, les soustrayant à toute autorité, les constitue fatalement en femmes publiques, au sens juridique, c'est-à-dire, sur le plan moral, en prostituées (p. 42). Les premières Ursulines françaises ont cru pouvoir profiter de ce no man's land pour inventer une vie religieuse hybride, car les décrets du Concile de Trente - séparant le sort de femmes et des hommes et décidant que la seule vie religieuse autorisée pour les premières se ferait dans les murs du cloître - ne sont reçus en France qu'en 1615.

5 Mais dès 1614, une Bulle pontificale décide que la clôture et la règle de saint Augustin s'appliquent aux Ursulines, qui, comme le montre L. Lux-Sterritt, en font paradoxalement la demande et l'acceptent, dans l'ensemble, sans beaucoup de difficulté (p. 65). Plusieurs remarques s'imposent ici: les documents d'archives consultés pour la province toulousaine (qui fournit la base documentaire de l'ouvrage) donnent peu de détails sur les refus qui ont pu être vifs, mais que les mémoires de fondation n'ont évidemment pas retenus. La dimension politique et juridique de l'affaire manque peut-être de quelques précisions dans l'ouvrage pour mieux saisir le rôle des « forces » en présence et les intérêts locaux qui entrent en jeu.

6 En tout cas, la virevolte fait accepter le cloître à celles qui le refusaient et qui faisaient de la vie mixte un cheval de Troie du militantisme catholique dans la cité. Ce retournement est expliqué de diverses manières: par la concurrence des ordres religieux féminins (comme les Clarisses) préférés par l'aristocratie qui finance les établissements; par la «diplomatie» (p. 65) de femmes conscientes du poids des états sociaux et de leurs effets économiques et moraux. Au fond, comme le note l'auteure, les premières Ursulines ont bien compris le poids du genre, comme construction sociale, et l'usage qu'elles devaient en faire dans leur « pragmatique » (p. 53). Si les Ursulines ont 
accepté la clôture, c'est donc, selon l'auteure, par stratégie, et dans une logique de réussite institutionnelle. L'avenir leur a donné raison. L'ordre cloîtré des Ursulines gagne la reconnaissance des familles de l'aristocratie du sud-ouest qui y envoient leurs filles pour une vie conventuelle ou pour y être éduquées avant le mariage. Grâce à un «tour de force » (p. 71) les Ursulines se plient à l'enfermement dans la vie monastique, mais pour mieux en sortir et entrer dans la vie civile, grâce aux élèves "externes ". Véritable sas entre le cloître et la ville, l'externat est, selon l'auteure, une pragmatique de l'activisme religieux : l'étude donnée du système des diverses portes qui ouvrent et ferment le cloître est, de ce point de vue, d'une grande pertinence et tout à fait étonnante (p. 143). L'architecture des cloîtres contribue à ce paradoxe d'un lieu $n i$ ouvert ni fermé, selon une topographie qui vise à empêcher l'intrusion du monde dans la vie des novices et à favoriser la pénétration religieuse dans le monde - par l'éducation et le livre - tout en régulant l'invasion des livres mondains vers l'intérieur.

7 L'étude menée en parallèle est consacrée à Mary Ward et à ces Dames Anglaises qu'elle essaie d'instituer au début du XVII ${ }^{e}$ siècle. L'intérêt de l'ouvrage est largement assuré par cette étude de deux cas : face aux Ursulines françaises, ce deuxième volet (dont l'auteure est spécialiste) justifie pleinement le titre choisi, qu'on peut traduire ainsi : Définitions (ou déclinaisons) au féminin de la vie religieuse.

8 Mary Ward est une anglaise récusante qui agit en Angleterre et depuis le continent pendant la persécution anti-catholique. Son cas confronte le lecteur à un dessein de résistance et de militantisme sans compromis. Là où les Ursulines adoptent stratégiquement la tutelle masculine et le rôle qu'on leur assigne derrière les murs, Mary Ward revendique explicitement et durablement, dans ses textes de fondation, une égalité entre les hommes et les femmes dans la sphère religieuse. De ce point de vue, elle adopte plus radicalement que les Ursulines françaises une prise de position genrée et la notion est scientifiquement utile. Le modèle de la Compagnie de Jésus lui offre les principes à partir desquels inventer un ordre séculier féminin. Cette modélisation, perçue comme une usurpation intolérable, lui vaut la suspicion et bientôt l'opposition violente et définitive de Rome : en 1631, une Bulle supprime les premières institutions, condamne la fondatrice comme hérétique et prononce son arrestation à Munich (p. 73, 196). Le terme péjoratif de "jésuitesses", comme on les appelle, met au jour l'audace des propositions de Mary Ward: loin de toute formation de compromis, elle revendique, selon un usage tactique stupéfiant, la faiblesse féminine comme moyen de lutte dans le monde pour subvenir aux besoins de l'Église en temps de persécution. Perçue comme une rebelle et une innovatrice dangereuse et manifeste, Mary Ward fait une appropriation politique des traits prêtés aux femmes, mais pour en subvertir les effets sociaux à l'intérieur de l'Église : obéissantes, faibles, chastes, peu actives dans le public et donc peu soupçonnables, les catholiques récusantes sont habituées à agir dans le privé et dans la clandestinité et sont, par là même, de formidables agents de liaison pour conserver et transmettre le catholicisme. De cette évidence d'un ethos féminin qu'on pourrait qualifier de faible, Mary Ward justifie l'invention d'un rôle genré dans l'Église qui convertit la faiblesse en force.

9 Les moyens de lutte adoptés par les récusantes et le rôle joué par certaines femmes (Anne Vaux, par exemple, p. 160) pour protéger les jésuites (comme le célèbre Henry Garnet) agissant clandestinement en Angleterre au début du siècle, ont sûrement contribué à la revendication d'une place que les femmes avaient inventée dans la pratique et qui manquait de la reconnaissance d'une institution lointaine et défiante. 
Habituée à la piété récusante qui obligeait les individus à s'engager dans la clandestinité par des vœux privés et dans les familles - véritables couvents laïques -, Mary Ward était capable d'inventer des moyens d'action, c'est-à-dire une pragmatique militante. Car la persécution oblige à trouver une nouvelle topologie de la vie religieuse : l'intérieur et le caché y sont nécessaires en période de contrainte, en sorte que le cloître, mais dissimulé dans la conscience et dans la vie familiale, y prend la place de toute forme visible et publiquement séparée. De ces modélisations, Mary Ward est consciente, comme si la pratique de la dissimulation rendue nécessaire à ces catholiques cachés la ramenait paradoxalement sur les terres médiévales de la dissidence et du séparatisme avec les formes officielles de l'Église visible.

L'examen de ces deux cas (une stratégie de soumission payante face à une tactique de résistance condamnée) nous montre que seules des études précises peuvent permettre une approche des usages genrés que des femmes catholiques ont mis en pratique pour parvenir à construire des rôles divers et des actions dans le monde.

11 L'ouvrage consacre un chapitre (ch. 4) à l'enseignement que les Ursulines et les Dames Anglaises choisissent d'investir : ni prêcheuses, ni prêtres, les femmes se lancent dans un apostolat éducatif dont les filles (surtout celles de milieux modestes) sont dans l'ensemble privées. Si la dimension disciplinaire et morale ne fait pas de doute, il faut aussi noter le rôle positif que l'apprentissage de la lecture a pu jouer dans l'accès des femmes à la culture. Mary Ward est plus attentive que les Ursulines françaises aux filles socialement peu dotées auxquelles transmettre de quoi lire les Écritures.

Les derniers chapitres de l'ouvrage ouvrent sur une question. Les Ursulines et les Dames Anglaises ont-elles été des rebelles, des émancipatrices? Ou seulement des religieuses, victimes consentantes ou aliénées, d'un pouvoir résolument masculin qui les a fait rentrer de gré ou de force dans la vie monastique ? Telle est la question que pose finalement l'auteure de ce livre. Si elle ne paraît pas forcément la mieux formulée, elle doit l'être, puisqu'elle pose de front les limites de l'interprétation. Tout dépend justement du rôle que l'opération critique fait jouer à la documentation examinée. L. Lux-Sterritt paraît parfois trop confiante dans des sources qui exposeraient de manière transparente la vérité des expériences religieuses. L'arsenal des pratiques de religiosité les plus anciennes (mortification, jeûne, etc.) examiné en fin d'ouvrage venant comme surplomber ses analyses pour constituer le fonds spirituel vrai des pratiques et des exigences sociales revendiquées.

13 La réponse à la question ne peut donc être que nuancée, car il faut reconnaître dans les sources le recours quasi systématique aux lieux communs des vies de religieuses. Il est également difficile de lire les écrits de Mary Ward sans tenir compte des effets stratégiques volontairement apologétiques, puisqu'il s'agit d'échapper à un jugement de l'Église qui la condamne ou de consoler celles qui l'accompagnent dans le jugement pour hérésie.

De ce point de vue - et c'est le seul reproche que nous formulerons -, il serait bienvenu de mieux distinguer les types de sources et d'en fournir des modes de lecture différenciés, plus attentifs au contexte d'énonciation et aux effets voulus, selon les règles d'une pragmatique dont l'auteure observerait plus finement le détail dans l'écriture. Certes, l'éducation des filles y est décrite comme le fruit d'un renoncement à la vie personnelle, à la famille naturelle, à l'amour de soi et comme le résultat de l'anéantissement de tous les biens symboliques que la société peut offrir. À ce renoncement ascétique doivent donc succéder des fruits spirituels qui, selon l'auteure, 
permettent aux Ursulines de figurer la classe comme un espace de donation de soi, puisque chaque élève est une partie de la multitude vers laquelle tend la mission. Ces éléments permettent-ils de décider de leur disposition à l'émancipation ou à l'aliénation? On peut en douter. Si les textes dévaluent l'action au profit de la contemplation, insistent sur l'intérieur spirituel plus que sur l'extérieur social sur lequel pourtant l'activisme éducatif débouche, il faudrait vérifier la nature de ces affirmations et le rôle qu'elles jouent dans le cadre d'une apologie pro domo.

Pour Mary Ward, l'opprobre, la prison, l'abandon par le pontife sont autant de manières de vivre comme le Christ, dans l'abandon à la volonté du Père. L'usage de la figure christique s'inscrit dans un langage mystique traditionnel, mais au féminin, inventant ainsi, dans un langage convenu et autorisé, une nouvelle grammaire et un rôle inouï pour le sujet qui l'énonce. C'est à l'intelligence de ces faits sociaux et religieux que ce livre contribue.

\section{AUTEURS}

\section{SOPHIE HOUDARD}

Université Paris III - Sorbonne Nouvelle 